\title{
The Surprise of a Breast Reconstruction: A Longitudinal Phenomenological Study to Women's Expectations About Reconstructive Surgery
}

\author{
Marjolein de Boer ${ }^{1} \cdot$ René van der Hulst ${ }^{2}$. \\ Jenny Slatman ${ }^{1}$
}

Published online: 27 August 2015

(C) The Author(s) 2015. This article is published with open access at Springerlink.com

\begin{abstract}
While having a breast reconstruction, women have certain expectations about their future breasted bodies. The aim of this paper is to describe and analyze these expectations in the process of reconstruction. By applying a qualitative, phenomenological study within a longitudinal research design, this paper acknowledges the temporarily complex, contextualized, embodied, and subjective nature of the phenomenon of expectations. The analysis identified expectations regarding three different aspects of women's embodiment: (1) their gazed body, (2) their capable/practical body, and (3) their felt body. After reconstruction, these women try to reconfigure-adjust, level or retrospectively rewrite-their expectations. Further, some women face what apparently arrives totally unexpected, namely a strange feeling breast or a failed reconstruction. The development of these women's expectations can be understood as an active, continuously evolving, difficult and sometimes impossible dynamic of expecting the surprise that is a breast reconstruction. Within this dynamic, women formulate and reconfigure-by definition-unrealistic expectations and validate and try to achieve unexpected futures. We suggest that medical professionals can facilitate this dynamic in various ways.
\end{abstract}

Keywords Breast reconstruction - Expectations · Bodily experiences · Phenomenology · Time consciousness · Qualitative research

Marjolein de Boer

m.deboer@maastrichtuniversity.nl

1 Department Health, Ethics and Society, Maastricht University, PO Box 616,

6200 MD Maastricht, The Netherlands

2 Department of Plastic, Reconstructive and Hand Surgery, Maastricht University Medical Centre, Maastricht, The Netherlands 


\section{Introduction}

Over the last decade, the demand for breast reconstructive surgery has increased thanks to, amongst other factors, the improved prognosis and survival rate of breast cancer and the possibility for screening BRCA 1/2-genes (Jagsi et al. 2014). Further, due to more available information about reconstruction, women are more likely to consider this post-mastectomy option (Losken et al. 2005). Those who opt for a reconstructive intervention undergo drastic and enduring bodily changes: not only do they get new breasts, they often also face a process of molding their new breast(s) through additional surgeries. Moreover, the procedure requires a long recovery and rehabilitation period and sometimes goes together with relapses or reconstruction failure. Being caught up in this life altering process, women pose various questions about their future breasts, their bodies, their lives and their relationships with others. How will I look? And how will it feel? Will I be in much pain? What will others think of the reconstruction? Is it - as the word presupposesa reconstruction of my old breast? These kinds of questions go together with certain expectations. This article analyzes the expectations women have about their breast reconstruction.

Research on this topic is mostly conducted within the field of health sciences. These studies mainly discuss whether women's expectations can be said to be realistic or not (Denford et al. 2011; Holtzmann and Timm 2005; Snell et al. 2010; Spector et al. 2010). Realistic expectations are generally understood as "anticipating an event or outcome [that] is likely to occur" (Wiles et al. 2008: 565) and they are associated with the patient's satisfaction about the end result (Iversen et al. 1998). In the case of having unrealistic expectations, then, this literature often debates the issue how women-patients can be facilitated by medical professionals in formulating (more) realistic expectations (Denford et al. 2011; Snell et al. 2010; Spector et al. 2010).

Several scholars offer a critical voice to this kind of research by stating that people may have different views about what is realistic to expect (Davison et al. 1991) and by arguing that medical professionals do not necessarily possess expert knowledge about what is realistic to expect, or at least that they are not the only experts (Hatt 1998). Moreover, various authors formulate the insight that expectations, their intensity and nature, may vary over time, in relation to other life events (Bury 1997; Wiles et al. 2008), and with regard to various aspects of embodiment such as appearance or sensitivity (Snell et al. 2010). Further, the rich tradition of sociology of expectations shows that expectations-its formulations and development-are socially mediated (Lindemann 2005; Luhmann 2014) and that expectations - rather than being explicitly articulated-may also be implicit and tacit (Garfinkel 1984). ${ }^{1}$

In this article we expand on this critical stance toward the dichotomy between realistic and unrealistic expectations, while focusing on the preliminary question of what having expectations actually means. Our aim is to analyze and describe

\footnotetext{
${ }^{1}$ We would like to thank an anonymous reviewer for drawing our attention to relevant studies within sociology of expectations and its implications for the interpretation of our empirical data.
} 
women's (possible) multiple bodily, ever-changing and contextualized expectations. To this purpose we present here the analysis and discussion of a qualitative and longitudinal empirical research which is explicitly framed within the philosophical phenomenological question of how we experience things and thus, of the meaning things have in our experience (Husserl 1960; Heidegger 1962). As shown in the next sections, by drawing specific attention to our contextualized, subjective, embodied and temporal experience, this framework offers a broader scope on the experience of expectations in comparison to the health science literature on this topic. As such, it contributes to unravelling the empirical complexities involved in expecting a breast reconstruction.

\section{Phenomenology of Expectations}

Central in the phenomenological exploration of expectations is the concept of intentional time consciousness. Husserl (1960) claims that consciousness is intentional in the sense that it is conscious of something. In the directedness of consciousness, intentional objects are constituted. In his work on time, furthermore, he argues that consciousness has a triadic temporal structure. That is, our experience always contains a reference to past moments, a subjective now-standpoint, and an anticipation to moments of experience that are about to happen but are not yet actual (Husserl 1960). Strictly speaking then, expectations belong to the future part of the triadic temporal structure of our experience. According to Husserl, the experience of expecting something connotes being intentionally directed towards future objects, towards something that will happen (Gallagher 1979; Husserl 1960). A phenomenology of expectations is therefore always a phenomenology of a becoming, of a not-yet (Heidegger 1977).

As expectations concern a yet-to-come, Gallagher (1979) contends, they direct us to a certain future possible happening which has the form of believing or being convinced that this possibility will occur. Although expectations implicate possibilities, this does not mean that this phenomenon precludes any actual position. Steinbock (2006) argues that unlike other orientations towards the futurelike hoping or wishing - the expectation's possibility is believed and anticipated as actually going to occur. Whereas hoping or wishing operates in the sphere of an open possibility - we can hope or wish anything, even if we do not believe that it will happen-expectations operate in the sphere of an actual possibility. Note that, as Steinbock writes, expectations and other orientations towards the future can be distinguished, they are also closely related. The object of our expectations may also be something we fear, want, wish or hope for, or our expectations may be motivated by our fears or desires.

Further, another kind of actuality is present in the so-called expected actual possibility. In expectations, we imagine future possibilities and we believe one of them will occur. Imagination, Ricoeur (1992) contends, is based on our own past experience or the represented experiences of others. That is, imagined possibilities are always slight and gradual modifications of actual (past) experiences of oneself or another. Expectations are thus altered as-if appearances of (past) experiences and 
actualities. As such, the phenomenon of expectations does not only belong to the future part of Husserl (1960) triadic temporal structure of our experience, but has to be understood as an entangled experience of the past, present and future. Having expectations now, Ricoeur (1992) asserts, involves positing a realm of future possibilities through imagination, something that is always already shaped by past experiences.

Taking the above-described characteristics of expectations into account, Dastur (2000) argues that this phenomenon has to be explored beyond its epistemology, beyond how time - the future, but also the present and past-is perceived and experienced within and through expectations. Rather, she asks, how do expectations appear within the context of their meaning? By believing that some possible happening will actually occur, Dastur points out, we attempt to fill in a yet-to-come and as such, we give meaning to and interpret what is by definition still unknown. We do so by positioning us on a delicate equilibrium between expectations' particular features: being moved by past, actual experiences; being convinced that something will actually occur; and being intentionally oriented towards future possibilities. Expectations as the attempted filling-in of a going-to-occur future through past-founded imaginations will never be completely fulfilled, she argues, since the mere idea of fulfillment of the expectation would destroy its basis, namely being intentionally oriented towards a future. In expecting, we remain in the mode of being open to the validation or invalidation of our convictions as it concerns an imagined and yet-to-come, unknown future. That is, however strong our belief of the happening of a certain future is, however convinced we are now that what will happen will be a modification of our past experience, it remains a conviction, an orientation towards a believed-to-come possibility rather than a yet-to-come determined (past-founded) actuality. In this sense, the event that is expected always comes - at least in part or to a certain degree - by surprise, as it is never completely how one expected it to be (Dastur 2000). Or, to quote Heraclitus, it is necessary to "expect the unexpected" (Heraclitus 1987 in Dastur 2000: 185). Paradoxically thus, through attempting to fill in the future, through having expectations, we have to be open to the indetermination of the future.

Ideally, this openness does not evaporate when the expected event has taken place. Linking up with the hermeneutical tradition, this article assumes that we constantly try to make sense of our future through fitting our expectations into our constantly changing life stories that express who we are, who we were, and who we will be (Ricoeur 1992). This means that while life unfolds, we attempt to formulate and reformulate, shape and reshape our former expectations and create new ones in light of our present and past experiences and always newly emerging future possibilities.

\section{Phenomenology as a Method to Explore Expectations About Breast Reconstruction}

Turning to our empirical investigation of women's expectations, we account for this phenomenology of expectations by using the qualitative research method of Interpretative Phenomenological Analysis within a longitudinal research design. 
This method is especially suitable for uncovering what having expectations actually means within the process of having reconstructive surgery because it strives for openness: for describing and interpreting experiences and sense making processes in their own, detailed, embodied and continually evolving terms within the subject's context (Murray and Holmes 2014; Smith et al. 2009). For this particular study, we conducted 26 in-depth interviews with ten women at different stages of their reconstructive process in order to investigate how these women develop and redevelop their expectations and how they continually make sense of the reconstructive experience. The resulting data is then analyzed through an inductive way of coding: attributing open, descriptive codes after which more general storylines emerge.

In the data collection phase, the first author interviewed the same seven women several times over the course of 1 year: before the reconstructive intervention, 3 months afterwards, 6 months afterwards and 1 year afterwards (October 2012February 2014). These women were recruited upon their first visit to the plastic surgery department of an academic hospital in the Netherlands. Out of this sample, one woman did not want to participate in the study anymore after her reconstruction. Another woman decided not to go through with the reconstruction after the first interview. The first author talked to her about this in a final second interview. Additionally, because (re-) developing expectations may well extend beyond 1 year after the reconstructive intervention, the first author interviewed three more women who had a breast reconstruction 5 years ago. These women were approached through their contact details in the archives of the same Dutch plastic surgery department. In total, 26 interviews were conducted with ten women.

Among these women are those who have unilateral (one breast) or bilateral (both breasts) reconstructions and immediate (during the same operation as the mastectomy) or delayed reconstructions (any number of years after the mastectomy). Further, this study includes women who opted for reconstruction following curative mastectomy (after the diagnosis breast cancer) and following preventive mastectomy (after the diagnosis BRCA $1 / 2$ gene). The age of the women in this study ranged from 28 to 75 at the time of the first interview (see Table 1 for an overview of the respondent's details). We obtained ethical clearance for this study from the hospital's ethical review board (File Number 13-4-086). Informed consent was obtained from all individual participants included in the study.

The interviews took place at the respondent's home, at the hospital or at another place of the respondent's choice. During the interviews, the women were initially encouraged to tell freely about their reconstructive experiences in general. By building on these women's stories, the interviewer zoomed in on those issues that are related to expectations. If necessary, the interviewer raised the issue of expectations herself. This resulted in interviews with a length ranging from $50 \mathrm{~min}$ to $2 \frac{1}{2} \mathrm{~h}$. All interviews were digitally recorded and transcribed verbatim. Upon transcription, all interviews were anonymized. Only the interviewer-also the first author-knows the identity of the respondents. In addition to the interviews, observation notes from the consultation room taken during the recruitment phase (one morning a week over a period of 4 months: October 2012-January 2013) 
Table 1 Respondent's details

\begin{tabular}{|c|c|c|c|c|c|c|c|}
\hline \multirow[t]{2}{*}{ Respondents } & \multirow[t]{2}{*}{ Age } & \multicolumn{5}{|c|}{ Interview moments } & \multirow{2}{*}{$\begin{array}{l}\text { Reconstruction and } \\
\text { mastectomy details }\end{array}$} \\
\hline & & Before & $\begin{array}{l}3 \text { months } \\
\text { after }\end{array}$ & $\begin{array}{l}6 \text { months } \\
\text { after }\end{array}$ & $\begin{array}{l}1 \text { year } \\
\text { after }\end{array}$ & $\begin{array}{l}5 \text { years } \\
\text { after }\end{array}$ & \\
\hline Doris & 33 & $\mathrm{X}$ & & & & & $\begin{array}{l}\text { Flap, bilateral, immediate, } \\
\text { curative }\end{array}$ \\
\hline Pamela & 68 & $\mathrm{X}$ & $X$ & $\mathrm{X}$ & $\mathrm{X}$ & & $\begin{array}{l}\text { Flap, bilateral, delayed, } \\
\text { curative }\end{array}$ \\
\hline Grace & 58 & $\mathrm{X}$ & $X$ & $\mathrm{X}$ & $\mathrm{X}$ & & $\begin{array}{l}\text { Implant, unilateral, } \\
\text { immediate, curative }\end{array}$ \\
\hline Mandy & 41 & $\mathrm{X}$ & $\mathrm{X}$ & $\mathrm{X}$ & $\mathrm{X}$ & & $\begin{array}{l}\text { Flap, bilateral, delayed, } \\
\text { curative }\end{array}$ \\
\hline Beatrix & 75 & $\mathrm{X}$ & $\mathrm{X}^{\mathrm{a}}$ & & & & $\begin{array}{l}\text { Flap, bilateral, delayed, } \\
\text { curative }\end{array}$ \\
\hline Marly & 61 & $X$ & $\mathrm{X}$ & $\mathrm{X}$ & $\mathrm{X}$ & & $\begin{array}{l}\text { Implant, unilateral, delayed, } \\
\text { curative }\end{array}$ \\
\hline Daphne & 29 & $\mathrm{X}$ & $\mathrm{X}$ & $\mathrm{X}$ & $\mathrm{X}$ & & $\begin{array}{l}\text { Flap, bilateral, immediate, } \\
\text { preventive }\end{array}$ \\
\hline Amelia & 45 & & & & & $\mathrm{X}$ & $\begin{array}{l}\text { Flap, unilateral, delayed, } \\
\text { curative }\end{array}$ \\
\hline Sally & 55 & & & & & $\mathrm{X}$ & $\begin{array}{l}\text { Flap, unilateral, immediate, } \\
\text { curative }\end{array}$ \\
\hline Barbara & 65 & & & & & $\mathrm{X}$ & $\begin{array}{l}\text { Implant, bilateral, delayed, } \\
\text { curative }\end{array}$ \\
\hline
\end{tabular}

${ }^{a}$ Did not have the reconstruction

were also included in the study. Quotes from the observation notes and interviews are translated from Dutch by the first author of this article.

In the analysis phase, the first author attributed descriptive, open codes to exerts of the interviews and observation notes that are related to the shaping and reshaping of expectations. Examples of these codes are "expectations before reconstruction: scarring," "no expectations before reconstruction," "expectations 3 months after: numbness breast" and "5 years after: unexpected feelings inside breast". On the basis of these codes, more general themes and storylines involving expectations about a breast reconstruction were identified in consultation with the last author of the article.

\section{Results}

Our analysis identified expectations prior to the intervention that refer to three different aspects of these women's embodiment, namely regarding their gazed body ("Expecting to look like a normal women"), their capable and practical body ("Expecting to have a practical and capable body"), and their felt body ("Expecting to feel a natural body"). As said, having expectations may also involve reconfiguring them, and these women do so in various ways. After reconstruction, they 
adjust the level of their initial expectations, they shift their focus from one (initial) expectation to another (new or old) one, and they (re-)write their initial expectations in retrospect ("Reconfiguring expectations"). Finally, some women face what apparently arrives as totally unexpected, namely their strange feeling breast or a failed reconstruction ("The unexpected").

Although we analytically distinguish between different kinds of bodily expectations before reconstruction and different kinds of reconfigurations and dealings afterwards, this does not mean that they are not interrelated in reality. As will be sketched out, these women's expectations, reconfigurations and other orientations towards their future intermingle and overlap in surprising and sometimes contradictory ways. Further, most women also have more than one kind of expectation or reconfiguration at one time and their expectations and dealings may also change over time.

\section{Expecting to Look Like a Normal Woman}

Expectations of looking normal, feminine and sexy occur again and again in the interviews. These kind of expectations seem to be incorporated in the understanding of reconstruction that permeates the practice of plastic surgery. Within the consultation room, we observed, there is a lot of talk about, and practices on how the reconstructed body should and will look. As such, women are mainly prepared for their postoperative appearance. For instance, many women are shown before and after pictures of other women's reconstructed breast(s). These pictures represent the successful 'realistic' cases, where the reconstructed breast resembles a 'normal breast,' but not too natural looking in order to prevent women from having too high 'unrealistic' expectations. Furthermore, many women are shown how they will look after reconstruction through the surgeon molding their original breast(s) or external prostheses. Daphne, who will have an immediate bilateral reconstruction, is one of them. She negotiates her future appearance while the surgeon is shaping her breasts:

Daphne: "Can they [the reconstructed breasts] come a bit more higher up?"

Surgeon: "Yes, yes, like this? And they will be a bit more firmer [than her original breasts]"

Daphne: "Nice [...] Then I will look like I did before I got children!" (Daphne, before reconstruction)

In reaction, the surgeon explains to Daphne that the reconstructed end-result will always be different than expected and will not be the same as her old breasts. Despite this warning, however, it seems that Daphne's expectations are shapedthrough negotiation and seeing her breasts being molded-by her memories of how she looked before she breast-fed her children. It may be argued that Daphne's expectation and the accompanying negotiating/molding activity points to Ucok's (2005) assumption that within the practice of reconstruction women merely conform to certain standards of feminine appearance, such as having young and sexy breasts. Even more, it may be argued that Daphne's case underscores the argument of feminist scholar Lorde (1980) that opting for such a surgical procedure implies 
unrealistic re-constructive expectations, namely to return to looking as we did before. In having a reconstruction, she argues, we are facilitated and even encouraged to expect merely the visual recurrence of past actualities. Reconstruction is therefore not only a gazed, normalizing practice according to Lorde, but also a misguided one: it stands in the way of getting used to and accepting the unavoidable new masectomized and scarred body (Lorde 1980). However valid this critique is, these women's expectations are-as we will see-less straightforward than they may look at first glance and point to a more complex reality of the reconstructive experience.

In the interview with Doris, 1 week before her reconstruction, we are coming back several times to her expectations regarding scarring. She says:

I think that the scarring will look bad and weird because they will cut you open from right to left, yes, and, of course, especially in the beginning with the wound and stuff. [...] But maybe after a while, I don't know, it will look better eh, when you put on a bra and t-shirt, nobody will see the scars and it will look normal again I guess. (Doris, before reconstruction)

Because of the scarring, Doris expects to only look normal again with clothes on. Also note the temporal dimension within this expectation of covert normality: Doris expects to look deviant "especially in the beginning" and only "after a while," she says, her reconstructed breast "will look normal," but still only with clothes on. This kind of expectation affects these womeńs expectations about dealing with their bodies in daily life, especially in situations in which nakedness is involved. For example, Pamela, who has a similar expectation as Doris, expects that after the reconstruction she will leave on a singlet while being intimate with her partner. For Doris and Pamela, their reconstruction is paradoxically presented as that which is expected to enable recovery from appearing deviant and that which signals deviance and, therefore, requires concealment.

For some women, however, it is very difficult to have expectations at all about how they will look after reconstruction, especially in relation to scarring. Before having an immediate unilateral reconstruction, Grace declares that:

I did look on the Internet and searched for photos [of reconstructed breasts] because [...] it might be good to see what you can expect. [...] But you know what it is? I am, I have a dark skin and on that [internet] page there were only white women. So I, I could not make a comparison with me. [...] I know for a fact that scar tissue heals differently with white women [than with dark skinned women]. [...] So it would have been nice to have some examples of negroid women, because now I cannot imagine how it will look like. (Grace, before reconstruction)

As the above quotes show, the issue of scarring and how this changes over time plays an important role in these women's expectations regarding their reconstructed appearance. Some expect to only look normal and feminine with their clothes on because of their-still deviant—scarred body. For Grace, imagining her scarred 
body seems to be impossible in itself because of the absence of appropriate (pictorially) represented experiences of similar (i.e., dark skinned) reconstructed bodies. As a result, it is difficult for her to have expectations at all about her scarred, reconstructed appearance.

\section{Expecting to have a Practical and Capable Body}

Women also articulate various expectations about their practical and capable body, a body that allows them to go around (more) easily. For many women who already had a mastectomy and wear external prostheses, the hassles of such prostheses lead to a discussion of the possibility of reconstruction as an alternative. Mandy, for example, reports that cleaning them, putting them in and out every morning and constantly having to pull them down is "annoying". Once she has the reconstruction, she says, "everything will be just normal again". Beatrix also seeks reconstruction as a practical alternative to wearing external prostheses, particularly while interacting with her grandchildren. She explains:

I babysit my grandchildren a lot, and if you just wear external prostheses, at the moment when you lift a child and especially in the summer months, everything will hang forward. It will get loose, you're sweating, you hear it every time when they flap back like 'flush,' a really strange sound [...] And you don't want to get your grandchildren a trauma because of that, it's weird enough that your grandmother does not have boobs. So that's why [she will have a reconstruction]. (Beatrix, before reconstruction)

Both Beatrix and Mandy expect that the reconstruction liberates them from constantly engaging with their prostheses: not having to clean them or not having to worry about strange sounds. Beatrix' words, moreover, show how such expectations may be socially mediated in complex ways. In line with Luhmann's (2014) argument that one's expectations may be based on one's expected expectations or preferences of others, Beatrix seems to expect that her grandchildren expect or anticipate her to have breasts, or at least to have a body that does not make strange sounds. In turn, Beatrix' expected expectations of her grandchildren seem to shape her view on what is significant to and expected from a breast reconstruction.

Additional to having a more practical body, some women also have expectations about their increased physical capability which in turn also has a liberating potential. Marly, for example, had a unilateral mastectomy 3 years ago and decided to have a reconstruction now that she feels that her mastectomy increasingly affects her capability. She is quite heavy breasted and with only one breast left, she walks crooked. Her hips, as a result, show signs of wear and walking hurts more and more. She expects that the weight of her new breast will help her to walk up straight again and to go around without having pain.

Other women do not have expectations about their capability in relation to the breasted end-result, but more in relation to the surgery itself. Commonly, these women find it rather difficult to formulate these kinds of expectations because of the unimaginability of pain that comes with having surgery and how it will affect them 
in daily routines. Like Pamela, who has a particular strategy in trying to overcome the difficulty in imagining what such an invasive operation will do to her:

I have nightmares about it [the operation] because it might hurt very much, but you can't imagine eh, you don't know what to expect and nobody can tell you how, where eh how it will hurt. And can I lift things? Can I even walk? [...] So I watch these shows [in which operations are broadcasted], but that does not help either really, or yeah, they don't show you if these women can wash the windows after the surgery [laughter]. But it will be okay, I'm sure. (Pamela, before reconstruction)

Pamela's strategy of watching the visual representation of the operation or even the pain of the patient does not sufficiently help her to imagine her felt pain after surgery and the capability of her body in recovery: extrapolating expectations about her future felt body and her resulting capability from visual representations of pain seems to be difficult. This difficulty may amount to the status of the involved senses. Phenomenologically speaking, subjectively felt experiences, like pain, are very intimate and are immediately accessible to the sensing subject (Husserl 1952; Lindemann 1997; Merleau-Ponty 1945; Ricoeur 1992). By contrast, visual experiences are characterized by distance and difference between what is observed and the observant-even when the observer and observant is the same subject-, and concern outer-instead of inner-states (Merleau-Ponty 1961). As such, imagining postsurgical pain and the resulting (in) capability may be difficult to extrapolate from a sensory mode that conveys external sensory perception (Lindemann 1997).

Curiously, after stating that Pamela is unable to formulate felt expectations, she adds that she is "sure" that it will be "okay". Perhaps this recovered-body expectation is based on the statistical information that most women will be "okay" after surgery, or perhaps it is motivated by her wanting or wishing to be able-bodied again. Either way, by repeating this expectation as a kind of mantra throughout the interview-especially after reporting having difficulties imagining and formulating expectations about her capable body-it seems that she tries to ward off her experienced difficulties and actively convinces herself that she may indeed expect a recovered body.

\section{Expecting to Feel a Natural Breasted Body}

In the interviews, women occasionally formulate explicit expectations about their felt body. These women expect different things with regard to sensitivity depending on what kind of reconstruction they will have. In general, there are two kinds of breast reconstructions: those that use artificial implants, and those that use the woman's own body tissue. In most of the implant reconstructions, a saline or silicone implant is placed beneath the skin. A breast reconstruction with one's own body tissue, a so called (free) flap-procedure, involves the removal of skin, muscle and fat from another part of the body, such as the abdomen, back or hip, and its transfer to the chest wall (Serletti et al. 2011). Other than with an implant 
reconstruction, a flap-reconstruction gets bigger or smaller when the body gains or loses weight.

Mandy, who will undergo flap-reconstruction, elaborates on her expectations about how the reconstructed breast will feel:

Well I don't know what I expect, but maybe that, that it is warmer, like my breasts always were, in comparison to a reconstruction with something artificial. It's hard to explain, but it is your own flesh after all, so I think, well I hope that... And blood runs through it, so yes, a more natural feeling. (Mandy, before reconstruction)

Marly, who will have an implant reconstruction, decided to have this kind of reconstruction also because of the sensory feeling aspect, but in a different way than Mandy does. She says:

I think... yes, that an implant reconstruction is less invasive because well, they only cut you open on your chest, not other area's [of the body]. And that is important because then, only the breast region is affected and other parts [of the body] remain intact, also feeling wise. You know, no cutting and stuff here [points to her belly]. (Marly, before reconstruction)

Marly's expectation about her implant reconstruction refers to the felt, "intact" body in general: to how her reconstruction will not affect or compromise sensitivity in other areas than the breast. Mandy's expectation about her flap-reconstruction refers mainly to the "own," "natural feeling" in the breast: own flesh, own blood and warm just like her "breasts always were".

Mandy and Marly are two of the few women that formulate expectations about their felt body. These kinds of expectations are less present in the interviews in comparison to expectations about appearance, practicability and capability. Moreover, felt body expectations are also less well-articulated than these latter kind of expectations. In the cases that these women talk about their felt expectations they seem to be unsure, hesitant, and falter. They pause a lot, use expressions like 'maybe,' 'I guess' or 'I don't know,' and some express contradictory statements. A possible explanation is that these women's difficulties stem from the fact that they did not give this kind of expectation much thought before the interview. Although some eventually do turn out to have felt expectations about their breasted bodiesremaining "intact" (Marly) and natural as they "always were" (Mandy) - these felt expectations seem to be tacit until the interviewer explicitly asks about them. Consequently, they still have to work out their story. However, even when these women already have extensively reflected on their future felt bodies, it remains difficult for most of them to formulate felt expectations. Beatrix, who is scheduled for a flap-reconstruction, is a good example of this. After the interviewer brings up the issue of feeling in the beginning of the interview she says she never thought about it. But now that she does, it still seems difficult to formulate these kinds of expectations. Towards the end of the interview she says: 
But I cannot imagine and that's just not possible, eh, what it is, if you transfer tissue from one place to another. And you take tissue from somewhere and that, then put it elsewhere, and eh, that is just really difficult when... regarding how it will feel, if it will have feeling at all. (Beatrix, before reconstruction)

Just 3 days after the interview, Beatrix called the interviewer to inform her that she decided to not have the reconstruction after all. She explains her reasons in a second interview:

No, no, I still cannot imagine. But it is the insecurity you know, you don't know what will come. If it will come back [the feeling of her breast] and how [it will come back]. And I am not up for that. It is good as it is. (Beatrix, before reconstruction)

Curiously, even after Beatrix thinks about her future felt body, it is not her expectations about it that makes her decide not to go through with the reconstruction, rather it is her lack of (being able to have) expectations. It is the extreme insecurity about her reconstructed felt future, unimaginibility even, that makes her not want to pursue this future.

The difficulties that women experience while formulating felt expectations may not only, as we have seen, point to attempting to build this kind of expectation on another sensory mode, but may also point to an inherent problem in imagining felt bodily experiences. Ricoeur (1992) argues that having expectations about your future body requires imagining yourself into several 'others': projecting yourself into an 'other,' future body through the re-presented experiences of a past 'other' self or of another person. In this sense, imagination involves the minimal distance of self-duplication: it contains an imagining (present) self-subject and an imagined (future, past, or alter-ego) self-object. This movement through otherness is a problem in imagining and expecting our future felt body. How our body feels for us is a very singular, momentarily experience. It corresponds to what Husserl has called the experience of one's own body as Leib, i.e., an experience of one's body that does not constitute observational content, and thus not an intentional object. Instead of providing physical qualities, the Leib experience constitutes a zero point for all action and perception (Husserl 1952). In line with Husserl, Ricoeur contends that this sensory experience "has no object, [...] it is the most intimate sense" (1992: 321; see also Lindemann 1997). If we feel pain or numbness, we feel it without distance, in this moment. It is difficult, then, to remember our own sensory feelings, let alone, to grasp how the body of another person feels like. As such, it is difficult for women to imagine and expect how their own 'other' future body will feel through re-presenting their own felt experiences or those of others.

\section{Reconfiguring Expectations}

After their reconstruction, women reconfigure their initial expectations and create new ones in multiple, complex and sometimes contradictory ways. Some women expect more or they may expect less, compared to their former expectation. Others shift their expectation focus to different kinds of expectations, and yet others retrospectively 
(re-)formulate their initial expectations. Within these reconfigurations, these women's former (gazed, capable, practical, or felt) expectations become closely entangled and intersected. Further, while new possible futures emerge, new and different kinds of expectations present themselves. Some women even (re-)configure their expectations up to a point that their newly created and their initial expectations cannot be distinguished anymore.

\section{Expecting more, Expecting Less}

The most common reconfiguration is to adjust the degree of the expectation: these women expect more or less with regard to their initial expectation. For instance, Pamela-who had difficulties with imagining her capable body in recovery-tells the interviewer 3 months after the reconstruction that walking up straight is a problem. Because of tissue taken from her abdomen and her skin being stitched together again, her belly is very tight. As a result, she walks a bit stooped. This affects her expectation about to what extent and within what period she will have a capable body again. She says:

And they [the surgeons] told me today that the recovery will at least take 3 more months. And I think oh God, 3 months, because I have to train myself with walking up straight again so the skin will get loose again. [...] So I have to lower my expectations a bit, no heavy lifting for now, that I, eh, but I am willing to give a great deal for it. (Pamela, 3 months after reconstruction)

Pamela's words show that she expects now that her body will be-at least temporarily-less able than she expected it would be before the reconstruction.

Conversely, other women reconfigure their expectation so they expect more from their future. At first, Grace could not imagine how her scarred body would look like. Every time the interviewer speaks to her after reconstruction, she sets her expectations regarding her gazed body higher and higher. 3 months after reconstruction she says:

I got B cup silicones, and don't get me wrong, they look beautiful. But because I've always got $\mathrm{C}$ cups, it is just not what it's used to be. It just looks funny, you know. So the doctor will call soon to make an appointment to adjust them, a bit bigger yes. (Grace, 3 months after reconstruction)

In the interview 9 months later, she says she is very pleased with the enlargement of her breast. Nonetheless, she now realizes that more medical procedures have to be done-a nipple reconstruction and the removal of scar tissue-in order to get, she says, the body "I eventually expect to have, [that] looks the most beautiful as possible".

Pamela's and Grace's quotes show that their adjusted expectations often assume various embodied activities and alterations on their part by and through which they work towards their expected future. For Pamela, this means doing exercises in order to stretch her skin, but it also means actively being passive-no heavy lifting-in order to allow her body to heal. In Grace's case, she up-scales her expectations, while choosing to have additional reconstructive procedures. 


\section{Shifting Expectations}

Some women reconfigure their expectations by partly shifting their expectation focus in the process of having a breast reconstruction. When the interviewer speaks to Marly 1 year after the reconstruction, her expectation to be able to walk up straight again is not actualized: the reconstructed breast was not heavy enough. Sporadically, she talks about this unfulfilled expectation: while searching for alternative options to make her breasts evenly heavy (i.e., through additional surgeries or wearing external prostheses), she seems to hold on to her expectation of eventually being able to walk up straight again. Meanwhile, her expectations regarding her gazed body come more to the foreground: while speaking about her future, she focuses more on her looks instead of her walking capabilities.

Other women have an expectation focus shift not because their former expectations were not met, but rather because new events take place: new people are met, and new interests unfold themselves. Amelia, who had an unilateral breast reconstruction 5 years ago, recounts her focus shift:

Yeah, it did not seem important at first but after a while you start to see the world again and become active with eh, men. And you just expect to be, well, feel natural you know, then. [...] And I also dance the tango and then you stand really close to each other. And then it becomes important. Because you do not want a man to notice the difference [between the reconstructed and the original breast] right away, I was anxious about that. [...] So I asked some good male friends to touch it and to tell me how they feel, whether they notice it [the difference between the breasts]. A kind of dry eh dry humping. (Amelia, 5 years after reconstruction)

Amelia formulates expectations about her tactile body when she starts being interested in having sexual partners again. Similar to Beatrix' socially mediated expectations, it seems that (projected) expectations of, in this case, male others about Amelia's body, makes Amelia shift her expectation focus (see Luhmann 2014). Note that this adjustment, just as with Grace and Pamela, comes with embodied activities. Amelia adopts a "dry humping" strategy to validate whether her tactile expectations are realized. Further, after one man says that her reconstructed breast feels harder than the other, she tweaks her reconstruction by putting soft tissues in her bra.

\section{Expecting in Retrospect}

Not only are women's expectations about their yet-to-come future reconfigured after reconstruction, interestingly, some women also retrospectively (re-)configure their former expectations-or lack thereof-about their already-happened future. Sally states that before the reconstruction she-like many other women-had difficulties with formulating expectations about her felt body. Now, 5 years after her unilateral reconstruction, she says she "know[s] what [she] should have expected," and even more how to explain it to others who will still have the reconstruction. She states: 
I showed them this [she puts her finger against the finger of the interviewer]. Now stroke with your other hand both fingers at the same time [she orders the interviewer]. This is how it [the feeling in her reconstructed and original breast] feels for me. (Sally, 5 years after reconstruction)

Sally not only configures the expectation she should have had before the reconstruction, she also tries to help other women in formulating their expectations by explaining how it feels for her.

An even more curious case of rewriting expectations is Barbara's reconfiguration. 5 years after her reconstruction she explains the feeling in her reconstructed breasts:

[Now they are] like a hard ball, it's not natural at all. [...] I remember being at the doctor's office [before reconstruction] talking about it [having reconstructed breasts] and how it would feel. And of course I thought, expected eh, I hoped it would feel natural, but I think I always knew in the back of my head that it would be different. [...] In a sense I always expected it to be this way, but yeah, you do not want that so you push it away I guess. (Barbara, 5 years after reconstruction)

Barbara's words bear witness of the complex temporality involved in having expectations. Her words may be interpreted as a way of rewriting the past and her former expectations, while taking into consideration her present experiences. She may have expected her breasts to feel natural before, but now that they don't, she says she always believed and implicitly expected-at least retrospectively-that they wouldn't. For her, the initial expectation did not actualize (primarily) because of the outcome, but (also) because it was-at least retrospectively-an unrealistic expectation to begin with. Barbara shows that having expectations is not an unambiguous matter of believing that a certain possibility will occur, as Gallagher (1979) and Steinbock (2006) seem to assume. In some way, Barbara believed and she didn't believe that her breasts would feel natural.

Further, in response to Steinbock's (2006) argued clear-cut distinction between different orientations towards the future, note that within Barbara's complex temporal narrative, various orientations like 'hoping,' 'wanting' and 'expecting' have an interesting interplay up to a point that they cannot be clearly distinguished anymore. At the time of the interview, Barbara says she did not want the expectation that she always actually-yet implicitly-expected that her reconstructed breasts wouldn't feel natural-, so she opted before the reconstruction for another expectation - that her reconstructed breasts would feel natural-that she now refers to as a mere hope.

\section{The Unexpected}

In a sense, every expectation incorporates the unexpected. As the above recounted cases show, these women reconfigure their expectations precisely because of the component of the unexpected inherent within their reconstructive experience which bring them towards unanticipated futures. Within their reconfigurations, they show 
that they are able to give new and altered meaning to their (expected/unexpected) experiences and to unfolding new possibilities. For some women, however, the event of the reconstruction fractures this possibility of giving meaning to their experiences and leaves them scattered, that is, unable to integrate the event of reconstruction within their life narrative. These women seem to experience the reconstruction as totally and destructively unexpected. This appears to happen in the case of a strange feeling breast and in the case of a failed reconstruction.

The most recounted unexpected experience is that of the felt breast. Before reconstruction, as Beatrix' and Sally's cases show, women often have difficulties with what to expect regarding their felt body. After the surgery, many of these women's reconstructed breasts feel numb or completely different from their former breast(s), something that they did not explicitly consider as a possibility or were not able to imagine and therefore appears to come totally unexpected. Like Daphne, who starts to cry when she tells the interviewer about the feeling in her breast 3 months after her reconstruction:

You felt it when you touched it, eh [short silence] but not felt, you did not feel it, also when you had an itch, and then you scratched and then you did not feel when you scratched it, but the itch goes away. Very, very strange. [...] Yes, not normal. [...] Just awful really, really, really awful. You cannot prepare for it. How, yes, how? (Daphne, 3 months after reconstruction)

Rather than interpreting Mandy's numbing experience as simply unexpected, we may argue that this experience is a breach of a very implicit felt expectation. Mandy's words suggest that she implicitly expected her present body to feel "normal," that is, more or less the same as it did before the reconstruction. As her current experiences are not those she had before, this expectation of continuation surfaces retrospectively in Mandy's story of-what may be understood asdisappointment (see Garfinkel 1984). Note that while we argued that it is difficult to formulate felt expectations because of the issue of immediacy and the problem of imaging another felt future, Mandy's case seems to show that formulating such expectations does not require imagining other futures per se, but may also involve extrapolating the present to the future.

Moreover, some unlucky women are confronted with the apparently totally unexpected event of a failed reconstruction. Although many of these women consider the event of a failed reconstruction as a (statistical) possibility ${ }^{2}$-and, in this sense, is foreseen -, when it actually happens, it still emerges unexpectedly. These women do not believe that their reconstruction will be unsuccessful. 3 months after the reconstruction, Mandy recounts the situation in which she heard that her reconstruction has failed:

So I said to the surgeon, yes but I smell corpses, I, I, yes, she [the surgeon] says thats because your breast is rotting away. And then I said, I was like, I cańt cope with this. [Now] I cannot look at that body anymore, I just avoid it. So that is very eh yes very hard, its very emotional. [long silence] But the

\footnotetext{
2 Percentages of unsuccessful reconstructions (i.e., removed tissue/implant due to complications) vary between different kinds of reconstructions (see IKNL 2012).
} 
smell, and yes, that sticks with you, yes, yes, thats so, so difficult. (Mandy, 3 months after reconstruction) ${ }^{3}$

Women like Daphne and Mandy speak of their (felt/failed) reconstruction in the mode of 'it happened to me'. They seem to experience no control over the event and its accompanying experiences, and in a way, it is the event which gives the order here (Dastur 2000). And that order, which swamps them, leaves them paralyzed and in chaos: they are not able to give meaning to this event and integrate it in the story of who they were, are, and will be. Daphne's strange feeling breast, for example, took her by surprise in such a way that a direct encounter with her present reconstructive experience seems to be impossible. She has trouble finding words and she only seems to be able to speak about her present experience in the second voice (you) and in the past tense. Mandy also avoids a direct, voluntary (visual) encounter with her present failed reconstruction. Even more, her experience neither allows her to reconfigure her former expectations, nor allows her to be open to other possible futures. She states that "I cannot have any expectations anymore. I won't [long silence]. This takes up too much". Women like Mandy and Daphne experience their incapacity to experience the traumatizing reconstructive event and, as a result, cannot interpret and give meaning to their present, past, and future.

However, these women are not completely paralyzed in relation to their unexpected reconstructive experiences: they keep trying to give meaning to it, though obscure and preliminary. In the three times the interviewer speaks to Daphne after reconstruction, she continues to try to find words for her numbing experience, although in a faltering, sometimes contradictory manner. Furthermore, Mandy finds herself involuntarily confronted with her failed reconstruction through the smell of the rejected body tissue that will not get out of her nose. As such, she seems to have to continue to deal with and speak about the failed reconstruction, thereby attempting to give meaning to it.

\section{Discussion and Conclusion}

Based on this analysis, we can draw three conclusions: (1) The multiplicity of women's expectations about breast reconstruction shows that the reconstructive experience adheres to all aspects of their bodily existence. (2) This range of expectations complicates the understanding of the breast reconstructive practice as a re-construction of a breasted past. (3) The development of these women's multiple expectations can be understood as an active and continuously evolving, difficult, and sometimes impossible dynamic of expecting the surprise that is a breast reconstruction. We suggest that medical professionals can facilitate this dynamic in various ways.

\footnotetext{
3 Needless to say, this quote represents this woman's subjective experiences and not necessarily what her doctor actually said in the described situation.
} 


\section{Multiple Bodily Expectations}

Feminist and health science literature generally portray breast reconstruction as a normalizing, 'gazed' practice. Lorde states, for example, that the practice of breast reconstruction rehearses the idea "that [women] are only what [they] look or appear" (Lorde 1980: 57). Similarly, health science research centers on expectations about postsurgical appearance, such as symmetry of the breasts and visibility of scar tissue, and the importance of realistically creating and adjusting them by medical professionals (Denford et al. 2011; Holtzmann and Timm 2005; Spector et al. 2010). As such, this literature seems to assume that this is the only aspect of these women's existence we need to address in preparing women for their reconstructive experience. Indeed, in this study, the most prominent and well-articulated expectations by the participating women are about normality and appearance. Such expectations seem to draw on larger socio-cultural, normative frameworks that women should look normal, feminine and sexy. Nevertheless, many interviewed women expect to still look scarred and deviant after reconstruction. Even more, in line with the very few health science studies that address other bodily expectations than only gazed ones (see Snell et al. 2010), our results show that women's expectations often implicate the whole range of their bodily existence. These women have expectations about the practicality, capability, and feeling of their reconstructed breast(s) and body. Therefore, reconstruction cannot be understood as merely a gazed practice. As such, appearance is not the only aspect of women's embodied existence we need to address within the process of reconstruction. Building on Snell et al. (2010) recommendation, preoperative consultation may be improved by providing women with information about what they may or may not expect regarding their capable, practical, and felt body, along with information regarding their gazed body.

\section{Re-Constructing Past and Future}

The range of these women's expectations about reconstruction demonstrate that they do not simply expect a re-construction. Counter to Lorde's (1980) fear that the reconstructive practice merely signals an expectation to return to a breasted pastsomething that will never be realized according to her-, these women's stories also indicate expectations of other futures. As we have seen, some women imagine and expect-however difficult it may be-a future with scarred, insensitive breasts and a body in recovery, something they did not experience before. These kind of expectations adhere to Ricoeur's (1992) argued triadic temporal structure of expectations. Within our present expectations about a future that is believed to occur, he argues, we refer to our past by slightly and gradually modifying those experiences just had. Although this may be the case for many women, this study shows that some of them, nevertheless, try to relate to an experience that is radically different from at least their own past experiences.

Moreover, the women that do expect some kind of return to their past, anticipate a future that is far more complex than what Lorde seems to assume: simply having breasts again. These women's expectations of a normally looking, practical, 
capable, painless, sensitive, silent, warm, and soft breasted body-indeed, just like they had before-can be interpreted as an expectation of a body that does not require constant care, attention, and devotion. This kind of expectation involves a rather implicit bodily experience: an experience of their body that retreats in the background and does not obstruct daily life; an experience of their body that is "absent" rather than present (Leder 1990). Here, Ricoeur's (1992) triadic temporal structure of expecting something takes on a specific temporal appearance. These women's present expectations about their future reconstructed body contain references to an implicit past experience-the body being absent-that only becomes a remembered, explicit experience in the present, while this experience is no longer actual. It seems, then, that their past, implicit-absent-bodily experience only becomes recognized as an experience in the first place in the present, when their body is explicitly present (i.e., not-absent) in all its hardness, numbness, painfulness, or noisiness. This means that these women's expectations based upon their past, absent bodily experience, can only be configured in the context of their present-in both meanings of the word-bodily experience.

\section{Actively Expecting the Surprise of a Breast Reconstruction}

In contrast to what its etymology may suggest, having expectations in the context of a breast reconstruction is not a matter of awaiting. Rather, it involves many activities. The health science literature on expecting a breast reconstruction often places the work involved on the side of the medical professionals: they are responsible for the creation and adjustment of realistic expectations and for living up to them through performing medical procedures. Meanwhile, women who are candidates for the procedure are assumed to be passive: they wait to see whether their externally imposed, preferably realistic expectations come to pass (Denford et al. 2011; Holtzmann and Timm 2005; Snell et al. 2010; Spector et al. 2010).

The women in this study, however, pursue various activities in their reconstructive process-often in relation to other people such as partners, friends, family and not the least: medical professionals. First of all, women deploy several strategies to imagine possible futures and formulate their expectations. Second, by taking up an active role in letting their expectations come to pass, they try to achieve their expected future. Third, these women validate whether their expected future did, in fact, come to pass. Last, these women reconfigure their expectations in light of their past and present experiences and newly emerging futures. By pursuing these kinds of activities, the women in this study confirm what Hatt (1998) already argued: medical professionals are not the only ones who have expert knowledge about what to expect. Women also inform themselves about this issue. As such, they share in the responsibility for creating and adjusting their expectations and living up to them through taking up a whole array of expectational activities.

We suggest that this joint work of both medical professionals and womenpatients may be facilitated by medical professionals in various ways. This means, first of all, that in healthcare settings medical professionals may operate as providers of information: not only informing women about what they may expect in relation to various bodily experiences, but also introducing them to a range of 
expectational-imagining, formulating, achieving, validating and reconfiguringactivities. Second, in order to do justice to the expectational work both medical professionals, women put in, we argue that a so-called informational approach should be complemented with an interpretive/hermeneutic approach (Emanuel and Emanuel 1992). This interpretive approach explicates expectations and its related facts and values, and explores how they are constructed. As shown, women's expectations and their factual and moral grounds are very personal and dynamic: they differ per individual and bodily experience and over contexts and time periods. Moreover, expectations (or lack thereof) turn out to be often ambiguous, conflicting, very implicit or inchoate. As such, medical professionals can only give adequate information and prioritize and select certain (medical) procedures when women's expectations are drawn out. In their turn, the women can only negotiate and navigate this information and these expectational activities when their expectations and related motives are articulated and elucidated. Thereby, the medical professional may work throughout the reconstructive process with the reconstruction candidate to explicate and explore her ever-changing expectations. This joint interpretative effort may take the form of medical professionals asking women open-ended questions like "what is important in a breast reconstruction for you?," "why?," "what do you expect regarding your capability just after reconstruction?," "and after a year?," "can you imagine how your reconstructed breast will feel?". The resulting dialogue may not only allow medical professionals to tailor-make their consultation and medical approach, but may also help these women to tease out and understand their (lack of) expectations and how to use this insight in the reconstructive process.

Despite the best efforts of both women and medical professionals, however, our results suggest that women will always be confronted with unexpected experiences and outcomes. That is, the eventual reconstructive experience never completely correlates with the initial expectation. Sometimes even, imagining and expecting a future reconstructed body appears to be very difficult to begin with. Having reconstructed breasts_-we may say with Dastur (2000) - always arrives, in some way and to a certain extent, by surprise. In reference to health science literature on expecting a breast reconstruction (Snell et al. 2010; Holtzmann and Timm 2005; Denford et al. 2011; Spector et al. 2010), it seems that these women attempt to formulate and reconfigure-by definition-unrealistic expectations and achieve and validate their-eventually always-unexpected future. Within this spectrum of unexpectedness, most women appear to be able to deal with the component of surprise by re-narrating their life stories. Some women's re-narrating ability, however, is stretched beyond its limits. Then, contrary to a fairly limited conceptualization of expectational work put forward by the existing expectation literature (see Denford et al. 2011; Spector et al. 2010), having expectations and jointly adjusting and (re-)working on them cannot be understood as primarily geared towards realizing one's reconstruction expectations. Rather, having expectations inherently means to try to be open to being transformed by the surprising event that is a breast reconstruction (Dastur 2000).

Again, achieving this openness may be part of a joint effort of women-patients and medical professionals. Medical professionals may inform these women of the 
unexpectedness ahead by saying that reality will always be different than expected. Additionally, medical professionals may directly facilitate these women's narrative sense making practices. By employing an interpretive approach throughout the process of reconstruction, medical professionals allow these women to (re-)tell their stories in their own terms, thereby helping them to (re-)fit their past experiences and newly emerging possibilities into their present life narrative. In this way, the dynamic of having expectations becomes a truly cooperative enterprise that involves both (re-)working on a believed-to-actually-occur reconstructed future and making sense of the unavoidable surprise that is a breast reconstruction.

Funding Information This research is funded by the Netherlands Organization for Scientific Research-NWO (VIDI-Grant 276-20-016).

Open Access This article is distributed under the terms of the Creative Commons Attribution 4.0 International License (http://creativecommons.org/licenses/by/4.0/), which permits unrestricted use, distribution, and reproduction in any medium, provided you give appropriate credit to the original author(s) and the source, provide a link to the Creative Commons license, and indicate if changes were made.

\section{References}

Bury, M. (1997). Health and illness in a changing society. Londen: Routledge.

Dastur, F. (2000). Phenomenology of the event: Waiting and surprise. Hypatia, 15(4), 178-189.

Davison, C., Davey-Smith, G., \& Frankel, S. (1991). Lay epidemiology and the prevention paradox: The implications of coronary candidacy for health education. Sociology of Health \& Illness, 13(1), 1-19.

Denford, S., Harcourt, D., Rubin, L., \& Pusic, A. (2011). Understand normality: A qualitative analysis of breast cancer patients concepts of normality after mastectomy and reconstructive surgery. PsychoOncology, 20(5), 553-558.

Emanuel, E. J., \& Emanuel, L. L. (1992). Four models of the physician-patient relationship. The Journal of American Medical Association, 267(16), 2221-2226.

Gallagher, S. (1979). Suggestions towards a revision of Husserl's phenomenology of time-consciousness. Man and World, 12(4), 445-464.

Garfinkel, H. (1984). Studies in ethnomethodology. Cambridge: Polity Press.

Hatt, G. (1998). Uncertainty in medical decision-making. In A. Petersen \& C. Waddell (Eds.), Health matters; a sociology of illness prevention and care (pp. 223-239). Buckingham: Open University Press.

Heidegger, M. (1962). Being and time. Oxford: Basil Blackwell.

Heidegger, M. (1977). Vier Seminare. Frankfurt am Main: Klostermann.

Heraclitus, (1987). Fragments: a text and translation. Toronto: University of Toronto Press.

Holtzmann, J. S., \& Timm, H. (2005). The experiences of and the nursing care for breast cancer patients undergoing immediate breast reconstruction. European Journal of Cancer Care, 14, 310-318.

Husserl, E. (1952). Ideas pertaining to a pure phenomenology and to a phenomenological philosophy, Second book. (R. Rojcewicz, \& A. Schuwer, Eds., Trans.) (1989). Dordrecht/Boston/London: Kluwer Academic Publishers.

Husserl, E. (1960). Cartesian meditations: an introduction to phenomenology. The Hague: Martinus Nijhoff.

Integraal Kanker Centrum Nederland (IKNL) (2012). Mammacarcinoom, landelijke richtlijn [Translation title: Mammacarcinoom, national guideline]. www.nvpc.nl Accessed 10 Oct 2014.

Iversen, M. D., et al. (1998). The prognostic importance of patient pre-operative expectations of surgery for lumbar spinal stenosis. Patient Education and Counseling, 34(2), 169-178. 
Jagsi, R., Jiang, J., Momoh, A. O., Alderman, A., Giordano, S. H., Buchholz, T. A., et al. (2014). Trends and variation in use of breast reconstruction in patients with breast cancer undergoing mastectomy in the united states. Journal of Clinical Oncology, 32(9), 919-926.

Leder, D. (1990). The absent body. Chicago: University of Chicago Press.

Lindemann, G. (1997). The body of gender difference. In K. Davis (Ed.), Embodied practices: Feminist perspectives on the body. London: Sage Publications Ltd.

Lindemann, G. (2005). The analysis of the borders of the social world: A challenge for sociological theory. Journal for the Theory of Social Behaviour, 35(1), 69-98.

Lorde, A. (1980). The cancer journals. London: Sheba Feminist Publishers.

Losken, A., Burke, R., Elliott, L. F., \& Carlson, G. W. (2005). Infonomics and breast reconstruction: Are patients using the internet? Annals of Plastic Surgery, 54(3), 247-250.

Luhmann, N. (2014). A sociological theory of law. New York: Routledge.

Merleau-Ponty, M. (1945). Phenomenology of perception. (C. Smith, Trans.) (1962). London and New York: Routledge.

Merleau-Ponty, M. (1961). Eye and mind. The Merleau-Ponty aesthetics reader. Philosophy and painting (pp. 121-149). (B. Smith, Trans.) (1993). Evanston: Northwestern University Press.

Murray, S. J., \& Holmes, D. (2014). Interpretative phenomenological analysis (IPA) and the ethics of body and place: Critical methodological reflections. Human Studies, 37(1), 15-30.

Ricoeur, P. (1992). Oneself as another. Chicago: University of Chicago Press.

Serletti, J. M., Fosnot, J., Nelson, J. A., Disa, J. J., \& Bucky, L. P. (2011). Breast reconstruction after breast cancer. Plastic and Reconstructive Surgery, 127(6), 124-135.

Smith, J. A., Flowers, P., \& Larkin, M. (2009). Interpretative phenomenological analysis. Theory, method and research. London: Sage.

Snell, L., McCarthy, C., Klassen, A., Cano, S., Rubin, L., Hurley, K., et al. (2010). Clarifying the expectations of patients undergoing implant breast reconstruction: a qualitative study. Plastic and Reconstructive Surgery, 126(6), 1825-1830.

Spector, D., Mayer, D. K., Knafl, K., \& Pusic, A. (2010). Not what i expected: Informational needs of women undergoing breast surgery. Plastic Surgery Nursing, 30(2), 70-74.

Steinbock, A.J. (2006). Time, otherness, and possibility in the experience of hope. In P. Vandevelde (Ed.), Issues in Interpretation Theory (pp. 271-289). Milwaukee: Marquette University Press.

Ucok, O. (2005). The meaning of appearance in surviving breast cancer. Human Studies, 28, 291-316.

Wiles, R., Cott, C., \& Gibson, B. E. (2008). Hope, expectations and recovery from illness: A narrative synthesis of qualitative research. Journal of Advanced Nursing, 64(6), 564-573. 